\title{
Strategies for optimizing the environmental profile of dwellings in a Belgian context: A consequential versus an attributional approach
}

\author{
Matthias Buyle ${ }^{\text {a, * }}$, Johan Braet ${ }^{\text {b, c }}$, Amaryllis Audenaert ${ }^{\text {a, b }}$, Wim Debacker ${ }^{\text {d, e }}$ \\ ${ }^{a}$ Energy and Materials in Infrastructure and Buildings (EMIB), Applied Engineering, University of Antwerp, Groenenborgerlaan 171, B-2020, Antwerpen, \\ Belgium \\ ${ }^{\mathrm{b}}$ Department Engineering Management, Applied Economics, University of Antwerp, Prinsstraat 13, B-2000, Antwerp, Belgium \\ ${ }^{\mathrm{c}}$ Department of Product Development, Design Sciences, University of Antwerp, Prinsstraat 13, B-2000, Antwerp, Belgium \\ d Unit Smart Energy and Built Environment, Flemish Institute for Technical Research (VITO), Boeretang 200, B-2400, Mol, Belgium \\ e Buildings and Districts, Energyville, Thor Park 8310, B-3600, Genk, Belgium
}

\section{A R T I C L E I N F O}

\section{Article history:}

Received 12 November 2015

Received in revised form

22 August 2016

Accepted 23 August 2016

Available online 31 August 2016

\section{Keywords:}

Life cycle assessment

Decision support

Attributional

Consequential

Environmental profile

\begin{abstract}
A B S T R A C T
To date, many tools and guidelines to reduce environmental impacts from a life cycle perspective are available concerning the construction sector. However, basically all of them are modelled according to an attributional approach and there is a lack of studies that develop strategies for improvement based on a consequential LCA. The goal of this paper is to analyze to what extent the results differ when both models are applied on the same case, a representative dwelling located in Niel, Belgium. A conceptual optimization scenario for insulated exterior cladding has been added as well to examine to what extent different models affect the ranking of improvement strategies. For both approaches, the same foreground data and energy calculations are used, but the underlying structure of the models is different. The starting point is an attributional scenario, based on a Belgian guidance document 'Environmental profile of building elements' (EPBE) published by the Public Waste Agency of Flanders. The results of the entire life cycle indicate differences between the approaches, in direct relationship to the underlying modelling assumptions. The discrepancy becomes more pronounced when looking at the separate materials so the effect is not damped as a consequence of the aggregation in life cycle phases. Especially the three most contributing materials (steel, concrete and brick) show clear differences. The optimization scenarios underline previous statement, since the ranking of the different solutions is not equal according to both approaches. This research points out the emergence of a discrepancy between results when different modelling approaches are applied. The consequential model that complements the attributional EPBE study is therefore a useful addition to provide information for decision-makers. This way, the right information is available for all type of decisions.
\end{abstract}

(c) 2016 Elsevier Ltd. All rights reserved.

\section{Introduction}

\subsection{General}

The growing environmental awareness of the last decades resulted in identifying the construction sector as one of the major targets for improvement. The building sector is responsible for nearly $40 \%$ of the global energy consumption, $30 \%$ of raw material

\footnotetext{
* Corresponding author.

E-mail addresses: matthias.buyle@uantwerpen.be (M. Buyle), johan.braet@ uantwerpen.be (J. Braet), amaryllis.audenaert@uantwerpen.be (A. Audenaert), wim.debacker@vito.be, wimdebacker@energyville.be (W. Debacker).
}

use, $25 \%$ of solid waste production, $25 \%$ of water use, $12 \%$ of land use, and $33 \%$ of the related global greenhouse gas (GHG) emissions (United Nations Environmental Programme and Sustainable Buildings and Climate Initiative, 2010, 2009). This awareness resulted in Europe in energy regulations such as Energy Performance of Buildings Directive (EPBD) 2002/91/EC and the revised EPBD 2010/31/EU issued by the European Union (European Parliament, 2010, 2002). But attention for the improvement of the environmental profile of construction materials and their waste treatment emerged as well and resulted for example in the development of Construction Product Regulations and the implementation of the European Waste Framework (European Parliament, 2011, 2008). But before any conclusions can be drawn about the environmental profile of buildings or their components, 
the environmental impact of the entire life cycle has to be investigated, based on the methodology of a life cycle assessment (LCA). This methodology is a commonly accepted way to assess the environmental impact of products or services. Despite the fact that LCA takes the entire life cycle into account, still many assumptions and methodological choices have to be made throughout a study, which can lead to different outcomes. Traditionally, attributional LCA (ALCA) and consequential LCA (CLCA) are considered to be the two main approaches, however, only in the last decade CLCA is becoming better known and more implemented (Zamagni et al., 2012). Over time, many definitions emerged describing the differences between ALCA and CLCA (Curran et al., 2005; Ekvall and Weidema, 2004; Weidema, 2003). In the general, ALCA is defined by its focus on describing the environmentally relevant flows within the chosen temporal window, while CLCA aims to describe how environmentally relevant flows will change in response to possible decisions. So in the case of ALCA, contributions are traced backwards in time, making use of data on specific or market average suppliers at a certain point in time. In the case of multifunctionality, impacts are allocated over the different outputs according to a certain ratio representing the relevant underlying causal relationship (EC-JRC-ies, 2010). CLCA on the other hand is market based and only takes the actual affected suppliers into account (Weidema, 2003; Weidema et al., 2009). Since economic forecasting involves a lot of uncertain factors, a scenario based approach is appropriate to provide robust results. This can be done on micro- or macro-level, where in the first case only the existing production capacity is affected while in the second case also changes in capital goods might occur (Weidema et al., 2009). The market based reasoning is also applicable on processes with multiple outputs. By-products are eliminated by including the counterbalancing products they substitute on the market, so allocation can be avoided by means of system expansion (Schmidt, 2015). This is also applicable on the end-of-life phase, with the discussion on how to take the benefits of recycling and reuse into account. In CLCA, the benefits are assigned to the end of the life cycle when recycled products replace other products on the market (recycling potential). In ALCA on the other hand, the benefits are often assigned to the selected materials (recycled content) (EC-JRC-ies, 2010). Since both approaches have their strengths and weaknesses, it is relevant to apply both, depending on the type of research questions.

\subsection{Current LCA practices in the built environment}

To date, multiple tools exist to support house owners, designers, architects and policy makers by providing information on the environmental profiles of dwellings and materials. Some of them are descriptive based rating tools that only follow the LCA methodology to a certain extent e.g., BREEAM (UK) (BREEAM International, 2013), others provide more detailed performance based environmental information on commonly used materials, e.g., Ecolizer 2.0 (BE) (Public Waste Agency of Flanders (2015)) and Nibe (NL) (Haas and Blass, 2015). All previous examples rely on the attributional approach, just like the most elaborated study in Flanders to date, 'Environmental profile of building elements' (EPBE) published by the Public Waste Agency of Flanders (Debacker et al., 2013a). The purpose of the latter is to assist designers, architects and building owners to reduce environmental impacts of a building over the entire lifetime at the design phase of the construction process by providing data on building components. EPBE (Debacker et al., 2013a) describes with an attributional modelling approach the current environmental profile of 115 building components. For identifying products that are on average produced with the lowest environmental profile, the approach of this tool makes sense. Provided that the allocation is done according to the drivers of the relevant environmental impacts. However when it is used for eco-design (so changes in future production are involved) or serves as basis for policy-making, the nature of the functional unit changes and it is necessary to take the consequences of such a decision into account. Especially in the Belgian context, but also in a broader international context, there is a lack of consequential studies concerning the construction sector to support the decision making (Blengini and Di Carlo, 2010; Buyle et al., 2013; Earles and Halog, 2011; Finnveden et al., 2009; Ramesh et al., 2010; Sharma et al., 2011).

Independently of the modelling approach, buildings however are special products that differ thoroughly from more controlled (industrial) processes. In the construction industry, a LCA study is therefore on average much more complex and uncertain because of multiple issues such as the long lifespan of the entire building, in combination with a shorter lifespan of some elements and components, the use of many different materials and processes, the unique character, design and geography of each building, the evolution of functions over time due to maintenance and retrofitting, etc. Therefore results of previous studies are not directly comparable, however still trends can be identified.

An overall trend is the dominance of the use phase, mainly with respect to space heating and cooling demands (Adalberth, 1997; Asif et al., 2007; Chau et al., 2015; Marceau and VanGeem, 2006; Matasci, 2006; Ortiz-Rodríguez et al., 2010; Peuportier, 2001). This is directly related to the long life span of buildings. Additionally, in low energy buildings also lighting and auxiliary energy can have an important contribution to the use phase (Blengini and Di Carlo, 2009; Debacker et al., 2013b). Most of the optimization scenarios focus on improving the level of insulation, complemented with high-performance technical installations. Blengini and $\mathrm{Di}$ Carlo investigated a low-energy dwelling in Italy and found that although the operational energy was 10 times lower compared to the reference standard house, the total environmental impact was only reduced by a factor two. Additionally, when the level of insulation and energy efficiency increases, the share of material related impacts increases, both in relative and absolute terms (Blengini and Di Carlo, 2009). Buyle et al. (2015) analyzed the influence of building type, level of insulation and different technical services in order to improve the environmental profile of Flemish dwellings. It was found that taking into account the current energy regulations, multiple non-hierarchic actions for improvement were relevant. A combination of a compact building design with one of the two following possible ways to reach a similar environmental optimum: firstly by following the current regulations for insulation complemented with the most efficient technical services, and secondly by an extensive reduction of energy losses - entailing a reduced (but not negligible) influence of the efficiency of technical services on the results. Himpe et al. (2013) come to similar conclusions for the Belgian situation by performing a LCEA. Another recent Belgian study by Stephan et al. $(2013,2012)$ pointed out that a passive house was preferable to a standard one, even if the embodied energy exceeds the operational energy in the passive scenario.

So when energy consumption is reduced, the reduction of impacts related to materials deserves more attention. However, there is no consensus on how this should be achieved, on neither of the level of materials or structural systems. For example, some studies assign a lower impact to dwellings composed of renewable materials such a wooden timber frame structures, while others conclude that because of the higher land use of wood, massive structures (brick, concrete, steel) have a lower environmental impact (Bawden et al., 2016; Feiz et al., 2015; Gerilla et al., 2007; Marceau and VanGeem, 2006; Mithraratne and Vale, 2004). Also building 
design and used materials are strongly correlated, a topic which covers more than reducing the surface-area-to-volume ratio to minimize heat losses (Buyle et al., 2015). Allacker (2012) states that there is a great potential for improving the environmental profile through building design. Annemans et al. (2012) worked on this topic as well and concluded that after operational energy is pushed back until a financial bearable point, a pure material optimization can reduce material related impacts by $21 \%$. However, when the building is designed for deconstruction and disassembly, building components can be replaced separately and reused afterwards. Such a strategy can decrease material related impacts even more, up to 35\% (Debacker et al., 2011). Rickwood et al. (2008), in contrast, demonstrated that in, an Australian context, the differences of life cycle energy between residential building types are rather small, since the energy benefits are often diminished due to the increased embodied energy related to structural requirements.

In the previous paragraphs it is demonstrated that energy efficiency, material selection and design are crucial topics to improve the environmental profile of residential buildings. However, all these conclusions are based on attributional studies. Vieira and Horvath (2008) analyzed different end-of-life (EOL) solutions for buildings and the use of concrete in particular. Markets are analyzed taking elasticity of the period in 1971-2004 into account and consider the markets in the USA as a proxy for global markets. A difference in results between the attributional and consequential approach was found, but the authors stated that 'the choice between the use of ALCA or CLCA for buildings may not be as critical a decision as expected', since the preferred optimization scenarios were identical for both approaches. Sandin et al. (2014) came to a similar conclusion comparing two alternative roof construction elements: glue-laminated wooden beams and steel frames: the results differ, but the overall conclusions stayed the same. Eriksson et al. (2012) investigated the influence of the construction of one million apartment flats per year with a wooden instead of a massive structure by 2030 in Sweden and Finland and a sensitivity analysis on a European scale. The scenarios on a national scale could not identify major shifts in forest management, only the macro scale scenario pointed out an important influence. Buyle et al. (2014) compared different optimization strategies for a Belgian apartment block and pointed out that especially when the energy market is involved, the results of optimization strategies could differ substantially.

\subsection{Research objectives}

This literature on LCA in the construction sector pointed out the growing importance of material related impacts, next to the classic topic of energy efficiency. However, so far these issues have mainly been analyzed from a static and attributional point of view. Especially when future scenarios are involved, there is a need for consequential studies with regard to the construction sector as well. So in this context, the goal of this research is to complement the (attributional) EPBE study with a consequential version so designers can apply information of the most appropriate approach to support decisions. For illustration purposes, a representative Flemish dwelling is selected and analyzed according to the two approaches. Some conceptual improvements will be investigated. Furthermore, the difference in ranking the environmental profile of optimization strategies when choosing a modelling approach (i.e. ALCA or CLCA) will be analyzed. The analyzed improvements are systems for thermal insulation and exterior cladding. Finally, to maximize the comparability and robustness of the results, a sensitivity analysis is included as well: a CLCA model with identical geographical system boundaries and corresponding transport scenarios as described in the ALCA model.

\section{Methods}

\subsection{Case study and optimization scenarios}

As described in Section 1, the main goal of this research is to compare the results according to an attributional and consequential approach, applied on the same case. The case study is part of a new development located in Niel, in the north of Flanders, Belgium. This development consists of a series of housing groups, each composed of three connected dwellings. The dwellings have a net floor surface of $117 \mathrm{~m}^{2}$, distributed over two floors and a habitable attic, and can accommodate four people. The main façade is oriented to the East (see Fig. 1). This dwelling is considered to be representative since the average size of new buildings in Belgium is approximately $102-107 \mathrm{~m}^{2}$ for the period 2008-2014 (Statistics Belgium, 2014). In the same period the yearly average share of new buildings is approximately $0.7 \%$. About $80 \%$ of the current Flemish building stock consists of single-family dwellings, though only $50 \%$ of the new buildings are single family dwelling (Heylen et al., 2007; Statistics Belgium, 2014). The dwelling under study has three bedrooms, comparable to $50 \%$ of the Flemish single family dwellings (Heylen et al., 2007). The dwelling is constructed in accordance to the Belgian building tradition, consisting of a massive structure with load-bearing masonry brick walls, air cavity and brick façade, concrete floor slabs and pitched roof (see Table 1). In line with other Belgian research and the EPBE study, the estimated lifespan of the building is 60 years, though individual components can have a shorter service life (Debacker et al., 2013a; Heylen et al., 2007; Himpe et al., 2013). The estimated service lives are derived from BCIS (UK) and SBR (NL), identical to the results of the entire dwelling (BCIS, 2006; Vissering et al., 2011). More details can be found in the Supplementary Material.

Additional to the analysis of the already built case study, a conceptual optimization for insulated exterior cladding systems was carried out. In Belgium, post-World War II residential buildings are traditionally composed of load-bearing masonry walls with an air cavity and in more recent buildings an insulation layer is included as well. However, due to the increasing requirements for insulation imposed by the European EPBD regulations and their Flemish implementation (referred to as EPB), the overall thickness of outer walls increased from $28 \mathrm{~cm}$ on average for non-insulated walls up to more than $50 \mathrm{~cm}$ for passive buildings (Cyx et al., 2011). In order to reduce the thickness of outer walls, multiple alternatives are available, some of which are commonly applied in other European countries. Since load bearing masonry walls are still the standard structural concept for Belgian dwellings, the optimization scenario concerns only the outer layers i.e., insulation and exterior cladding. All scenarios have the same thermal performance, complying with the Flemish EPB regulations of 2015, with a u-value of $0.24 \mathrm{~W} /\left(\mathrm{m}^{2} \cdot \mathrm{K}\right)$. So only production, replacements and the end-of-life treatment is taken into account. The included scenarios and their properties are listed in Table 2.

\subsection{Research structure}

Attributional and consequential LCA try to answer different research questions, but the object of study and functional unit is the same. The functional unit is defined as follows:

A single semi-detached dwelling located in Flanders (Belgium) with a net floor area of $117 \mathrm{~m}^{2}$ and an estimated life span of 60 years.

Similar for the optimization scenarios:

One square meter of insulated exterior cladding system, attached to a load bearing masonry wall, with a thermal 


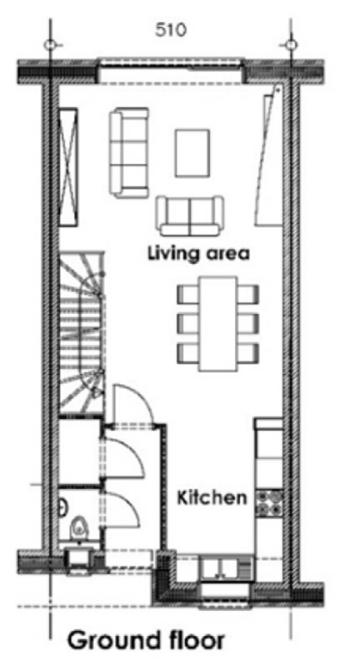

(a)

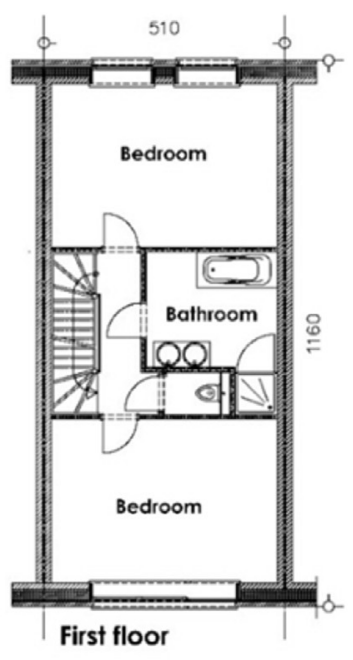

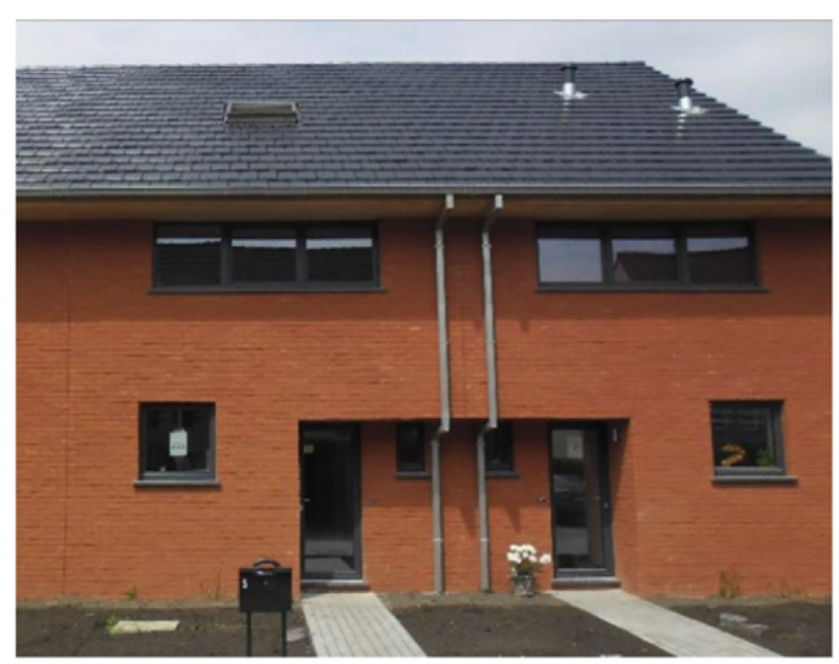

(b)

Fig. 1. (a) Floor plans; (b) view of front façade.

Table 1

Composition building elements.

\begin{tabular}{|c|c|c|c|}
\hline Element & Composition & Thickness $(m)$ & U-value $\left(W /\left(m^{2} \cdot K\right)\right)$ \\
\hline Floor slab & In situ reinforced concrete slab, PUR, screed, ceramic tiles & 0.30 & 0.28 \\
\hline Cavity & Gypsum plaster, brickwork, PUR, air cavity, brick façade stone & 0.34 & 0.23 \\
\hline Pitched roof & Gypsum plasterboard, timber frame, glass wool (between rafters), ceramic roof tiles & 0.21 & 0.22 \\
\hline Windows & PVC frame, double glazing & - & $1.68-1.75$ \\
\hline
\end{tabular}

Table 2

Optimization scenarios exterior cladding.

\begin{tabular}{|c|c|c|c|c|}
\hline Building element & Composition & Service life $(y r)$ & Replace-ments & Thickness $(m)$ \\
\hline Cavity wall - rock wool & Rock wool $12 \mathrm{~cm}$, air cavity, facing brick & $60-100$ & 0 & 0.38 \\
\hline Cavity wall - PUR & PUR $8 \mathrm{~cm}$, air cavity, facing brick & $60-100$ & 0 & 0.34 \\
\hline Synthetic plaster - EPS & EPS $12 \mathrm{~cm}$, reinforcing mesh, synthetic plaster & $15-25$ & 2 & 0.28 \\
\hline Synthetic plaster - PUR & PUR $10 \mathrm{~cm}$, reinforcing mesh, synthetic plaster & $15-25$ & 2 & 0.26 \\
\hline Synthetic plaster - rock wool & Rock wool $14 \mathrm{~cm}$, reinforcing mesh, synthetic plaster & $15-25$ & 2 & 0.30 \\
\hline Facade panels - wooden structure & Timber frame, rock wool $15 \mathrm{~cm}$, membranes, air cavity, fiber cement facing tiles & 30 & 1 & 0.34 \\
\hline Facade panels - aluminium structure & Aluminium frame, PUR $14 \mathrm{~cm}$, membranes, air cavity, fiber cement facing tiles & 30 & 1 & 0.33 \\
\hline
\end{tabular}

transmittance (U-value) of $0.24 \mathrm{~W} /\left(\mathrm{m}^{2} \cdot \mathrm{K}\right)$ and an estimated life span of 60 years.

The differences occur in the field of application of the results, where this functional unit represents a current dwelling in ALCA and a future building or an addition to the building stock in CLCA. Besides the general modelling assumptions described in the introduction, specific to this case study it means that generic data is applied, as EPBE is a guidance document at societal level. However the geographical delimitation is different for both approaches. In ALCA it is assumed that basically all building products on the Belgian market are produced in Western-Europe. Only some exceptions are made such as wood, with a large share of import from outside the EU borders and ceramic tiles which are mainly produced in Italy and Spain. As a default in CLCA, it is assumed that all markets are global, unless the existence of local markets can be justified. The analysis of the geographical delimitation, along with the identification with the affected suppliers, has been performed more in detail for the most contributing material groups. For other products and processes default values have been applied. This research focusses on the long term, so it is assumed markets are fully elastic.

Besides the general standards of the ISO 14040-series, EPBE (and the attributional model) to a great extent follows also an additional guidance specific for the construction sector developed by the European Committee for Standardization (CEN). A major difference is that more impact categories have been taken into account, which are weighted to a single score based on external costing. To improve the comparability of results between different studies, the CEN Technical Committee 350 "Sustainability of construction works" (CEN TC 350) developed standards for assessing all three aspects of sustainability (economic, environmental, social) both for new and existing construction works and for facilitating the integration of Environmental Product Declarations (EPDs) of construction products. This framework is composed of a modular structure, with more specific calculation rules compared to the ISO 14040-series. Similar to the EPBE study, in the attributional model all mandatory modules are included as defined in the standards EN 15804 and EN 15978: production and construction (A), use (B), and end of life stage (C) (European committee for Standardiation, 2012; 2011). The optional module $\mathrm{D}$ concerning recycling and reuse has an inherently different (and consequential) modelling logic and is excluded 
to prevent confusion. The life cycle environmental impact is defined in Formula (1) Some modules are excluded as a simplification such as maintenance, repair and refurbishment (B2, B3, B5) or because their contribution is assumed to be negligible such as impacts related to the erection of the initial construction (A5).

$$
\begin{aligned}
L E I= & \left\{E I_{A 1-A 3}+E I_{A 4}\right\}+\left\{E I_{B 1}+E I_{B 4}+E I_{B 6}+E I_{B 7}\right\}+\left\{E I_{C 1}\right. \\
& \left.+E I_{C 2}+E I_{C 3}+E I_{C 4}\right\}
\end{aligned}
$$

where:

- LEI: total environmental impact over the entire life cycle

- $E I_{x}$ : environmental impact within life cycle stage $\mathrm{x}$

- A1-3: production of construction materials (cradle-to-gate)

- A4: transport to and from construction site

- B1: use (land use parcel)

- B4: replacement of components during the use phase

- B6: operational energy use

- B7: operational water use

- C1: deconstruction

- C2: transport to disposal/treatment facilities

- C3: waste processing

- C4: final disposal

The functional unit is identical for both approaches, so the used foreground data is identical as well. The construction team delivered all data concerning the actual situation (drawings, bill of quantities) and the other data were simulated accordingly. The energy calculations were carried out by using EPB software Flanders (version 1.8.3), a static calculation tool used to verify compliance with the energy requirements but it can also be used to estimate the yearly energy consumption as well. The estimated water use is derived from Belgian statistics (Statistics Belgium, 2012). The replacement rates are based on the expected service life as described by BCIS (UK) (BCIS, 2006) and SBR (Vissering et al., 2011) (NL). All data are derived from Ecoinvent 3.1 (default products) and if necessary adapted to meet the modelling assumptions (Weidema et al., 2013). As described in the EPBE study, only the top level of the pedigree of the background data is harmonized to the research assumptions as it is assumed the influence of the harmonization of lower levels is negligible. EPBE provides data on transport- and end-of-life-scenarios as well, relevant for the Belgian context. Since the transport scenarios for the construction materials are related to the geographical delimitation, these are only implemented in the attributional approach. For the consequential approach, the global transport scenarios of Ecoinvent 3.1 are maintained. The end-of-life scenarios on the other hand are relevant for both models, even if recycling is cut-off in ALCA while the entire treatment process and substitution of recycled products on the market is included in CLCA. The system boundaries and included life cycle stages are displayed in Figs. 2 and 3.

Finally, an additional scenario has been included as a sensitivity analysis. This is scenario follows the consequential approach as described in the previous paragraph, but some adaptions are made to make it correspond more closely to the original EPBE study. The two main differences are geographical coverage and transport scenarios. Instead of the default assumption of global markets, the same geographical delimitation as in the attributional and described in the EPBE-study have been applied. So the default is a Western-Europe instead of global market. Transport scenarios have been adapted accordingly.

For more details on assumptions and LCI, see the Supplementary Material.

\subsection{Life cycle impact assessment}

As the impact assessment is independent of the chosen approach (ALCA vs. CLCA) only one impact method will be applied. This is a deviation from the CEN TC 350 framework, which describes its own set of midpoint categories. However, to facilitate interpretation of the results a single score indicator is applied, namely the ReCiPe Endpoint method with a Hierarchist perspective (1.10), which is considered as the default model (Goedkoop et al., 2012). Previous research pointed out the importance of the choice of impact method as incorporated value choices can affect the results, but since the main goal of this research is to evaluate different modelling approaches, no sensitivity analysis is added by using various impact methods (Buyle et al., 2013, 2011; Finnveden et al., 2006).

In first place the results of the entire life cycle will be investigated and the distribution of this impact over the different phases. This general analysis is complemented by a contribution analysis. The third step is the analysis of the optimization scenario to see whether the choice of research approach has an influence on the preference for certain scenarios. Finally, a comparison is made as sensitivity analysis between regular models and the additional consequential model.

A final remark concerns the presentation and visualization of the results. It is important to note that EN 15804 does not allow for aggregation of results and EN 15978 only allows it at the level of a life cycle stage when all modules are included. Since the main goal of this research is to compare the results of different modelling approaches, the different results per life cycle stage (modules) are added up. This way results become more readable and on the other hand the linked and market based approach of CLCA makes it hard to split up the results in the rather strict categories of the CEN TC 350 framework.

\section{Results}

Environmental impacts were first compared over the entire life cycle. In the following paragraphs, the attributional approach is considered as the reference when comparing both approaches. The overall results shows a discrepancy of $2.7 \%$ of the total impact (see Table 3 and Fig. 4). When distributing the impact over the different life cycle phases, it appears the ratio between the phases is completely different. Some of these differences seem logical; for instance the lower impact of the production stage of ALCA due to recycled content of materials and the negative values of end-of-life of CLCA due to recycling benefits. In addition, when taking only material-related impacts into account, the discrepancy increases to over $8 \%$. The difference in the impacts of the use phase is lower, mainly due to an almost identical impact of natural gas for both approaches, used for space heating. The largest difference can be observed at the water consumption during the use phase. The reason behind this is a typical example of the differences of the underlying models: the unconstrained marginal treatment technologies differ substantially from the current market average. Since a wide variety of materials is used in a dwelling, possible differences in the results are leveled out due to the aggregation. This topic will be elaborated more in detail in the next paragraph, however, it should be noticed that there is a big difference between the initial materials and the ones used for replacements.

The previous paragraph showed a difference of over $8 \%$ when only considering construction materials. Table 4 shows the 15 main contributing materials over the entire life cycle, so excluding land use of the building site, energy and water consumption of the use phase. Especially the materials with the biggest contribution show a clear discrepancy between the approaches. This discrepancy goes 
- C2: transport to disposal/treatment facilities

- C3: waste processing

- C4: final disposal

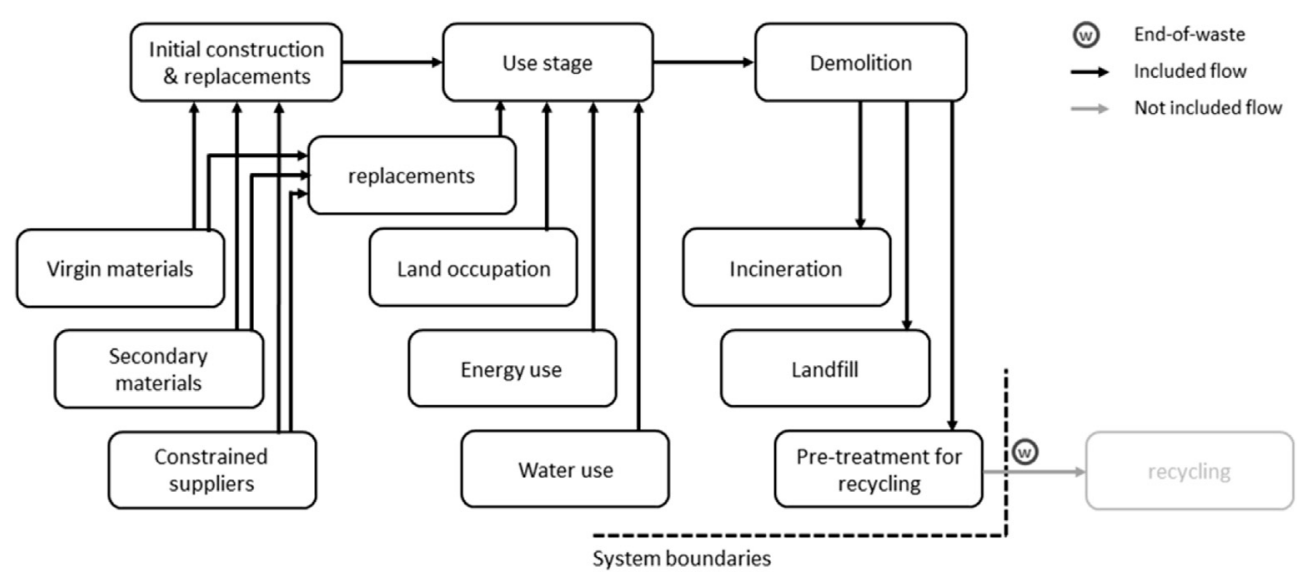

Fig. 2. System boundaries attributional model. End-of-waste system boundary according to annex B EN15804 + A1:2013.

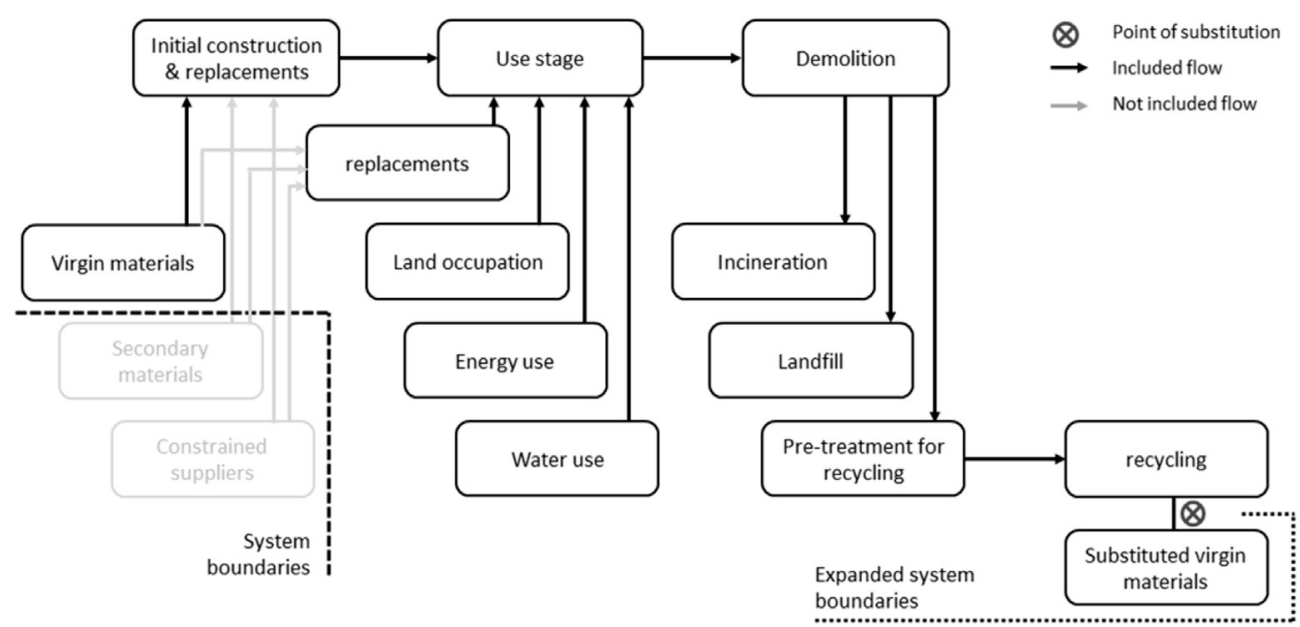

Fig. 3. System boundaries consequential model.

Table 3

Comparison LCIA of the individual life cycle stages and entire life cycle, including sensitivity analysis.

\begin{tabular}{|c|c|c|c|c|c|c|c|}
\hline & $\begin{array}{l}\text { Construction } \\
(P t)\end{array}$ & $\begin{array}{l}\text { Land use building site } \\
(P t)\end{array}$ & $\begin{array}{l}\text { Use phase -replacements } \\
(P t)\end{array}$ & $\begin{array}{l}\text { Use phase - water } \\
(P t)\end{array}$ & $\begin{array}{l}\text { Use phase - energy } \\
(P t)\end{array}$ & $\begin{array}{l}\text { End-of-life } \\
(P t)\end{array}$ & $\begin{array}{l}\text { Total } \\
(P t)\end{array}$ \\
\hline ALCA & 5940 & 167 & 3320 & 401 & 17,820 & 605 & 28,259 \\
\hline CLCA & 7750 & 167 & 3920 & 633 & 17,540 & -1010 & 29,010 \\
\hline CLCA - sensitivity & 6830 & 167 & 3680 & 633 & 17,540 & -839 & 28,020 \\
\hline ALCA vs. CLCA & $30.6 \%$ & $0.0 \%$ & $17.9 \%$ & $57,9 \%$ & $-1.6 \%$ & $-266 \%$ & $2.7 \%$ \\
\hline $\begin{array}{l}\text { ALCA vs. CLCA (materials } \\
\text { only) }\end{array}$ & $30.6 \%$ & - & $17.9 \%$ & - & - & $-266 \%$ & $8.1 \%$ \\
\hline
\end{tabular}

both ways, which explains why the differences are not so pronounced in the aggregated results.

Concrete is the material with the biggest impact, mainly due to the production of cement. Cement can be manufactured from clinker (Portland cement) or from ground granulated blast-furnace slag (GGBFS), a dependent and therefore constrained by-product of steel production. In the Belgian construction sector GGBFS cement has an important share, especially for in situ applications, but since it relies on a dependent by-product, it is constrained. Clinker production, which is not constrained, is an energy intensive process, so it is obvious that concrete has a larger environmental impact when it is modelled consequentially. The second most contributing material group is structural steel. Recycling rate (41\%) vs. Recycling potential (95\%) turns out to be the main reason for the deviation. Besides some small losses, steel can be recycled completely with minimal loss of quality and therefore reduces the demand for virgin steel. On the other hand the demand for steel is higher than the supply of iron scrap, resulting in a recycled content in the attributional approach that is well below the recycling potential in CLCA. The modelling of by-products plays a role as well, where in CLCA GGBFS replaces clinker, while a cut off is applied in ALCA. The previous reasoning about end-of-life treatment is also applicable 


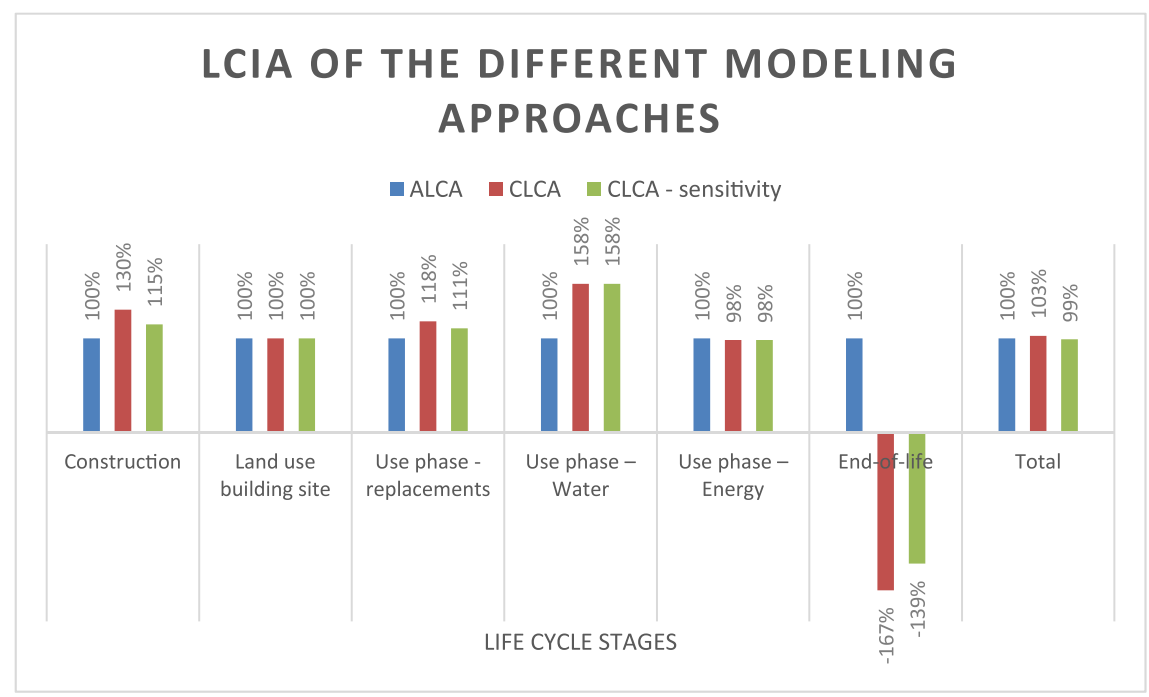

Fig. 4. LCIA of the different modelling approaches. ALCA is the reference scenario.

Table 4

Process contribution materials and sensitivity analysis.

\begin{tabular}{|c|c|c|c|c|c|c|c|c|}
\hline \multirow[t]{2}{*}{ Process name } & \multicolumn{2}{|l|}{ ALCA } & \multicolumn{2}{|l|}{ CLCA } & \multicolumn{2}{|c|}{$\begin{array}{l}\text { CLCA - } \\
\text { sensitivity }\end{array}$} & \multicolumn{2}{|l|}{ Comparison } \\
\hline & Pt & $\%$ & $P t$ & $\%$ & $P t$ & $\%$ & Difference ALCA vs. CLCA (Pt) & Difference CLCA vs. CLCA sensitivity $(P t)$ \\
\hline Concrete & 1990 & $20.7 \%$ & 2.347 & $22.4 \%$ & 1970 & $18.7 \%$ & 354 & -377 \\
\hline Structural steel & 919 & $9.6 \%$ & 633 & $6.1 \%$ & 611 & $5.8 \%$ & -286 & -22 \\
\hline Brick & 861 & $9.0 \%$ & 735 & $7.0 \%$ & 840 & $8.0 \%$ & -125 & 105 \\
\hline Alkyd paint & 667 & $6.9 \%$ & 596 & $5.7 \%$ & 518 & $4.9 \%$ & -71 & -78 \\
\hline Ceramic tile & 391 & $4.1 \%$ & 353 & $3.4 \%$ & 383 & $3.6 \%$ & -38 & 30 \\
\hline Window frame (PVC) & 380 & $4.0 \%$ & 446 & $4.3 \%$ & 452 & $4.3 \%$ & 66 & 6 \\
\hline Copper & 213 & $2.2 \%$ & 173 & $1.7 \%$ & 173 & $1.6 \%$ & -40 & 0 \\
\hline Cement mortar & 210 & $2.2 \%$ & 228 & $2.2 \%$ & 191 & $1.8 \%$ & 18 & -37 \\
\hline Autoclaved aerated concrete block & 194 & $2.0 \%$ & 213 & $2.0 \%$ & 209 & $2.0 \%$ & 19 & -4 \\
\hline Sawnwood (softwood) & 170 & $1.8 \%$ & 196 & $1.9 \%$ & 196 & $1.9 \%$ & 26 & 0 \\
\hline Polyurethane insulation & 166 & $1.7 \%$ & 172 & $1.6 \%$ & 225 & $2.1 \%$ & 6 & 53 \\
\hline Zinc & 162 & $1.7 \%$ & 89 & $0.9 \%$ & 90 & $0.9 \%$ & -72 & 1 \\
\hline Fiberboard & 148 & $1.5 \%$ & 186 & $1.8 \%$ & 156 & $1.5 \%$ & 37 & -30 \\
\hline Glass & 139 & $1.5 \%$ & 135 & $1.3 \%$ & 129 & $1.2 \%$ & -4 & -6 \\
\hline Glass wool insulation & 119 & $1.2 \%$ & 136 & $1.3 \%$ & 135 & $1.3 \%$ & 18 & -1 \\
\hline
\end{tabular}

on bricks and PVC window frames. Bricks barely contain any recycled material, but can be used after treatment for example as road foundation. The recycling market for PVC is still immature resulting in a negligible recycled content, however window profiles are easy to separate and recycle, resulting in a much higher recycling potential. A quite different type material is paint, with a relative high contribution due to the high replacement frequency. During the production of titanium dioxide, Ilmenite is needed which is co-mined with magnetite. In the attributional model, this is solved by applying revenue allocation, while in the consequential model magnetite is substituted on the market resulting in an overall lower impact.

It is important to keep in mind that the differences described in the previous paragraph are not the only possible explanation. Foreground scenarios can play a role as well, for example the difference for sawn wood can mainly be explained by the selection of the regional markets. The difference in transport scenarios of EPBE and the consequential model (Ecoinvent v3.1) is another element the might contribute to the divergence between de models.

Looking at the results of the optimization scenarios presented in Table 5, the ranking of the cladding systems is different for the two approaches. A synthetic plaster on EPS insulation is preferred in

Table 5

Optimization scenarios.

\begin{tabular}{|c|c|c|c|c|c|c|}
\hline \multirow[t]{2}{*}{ Optimization scenario } & \multicolumn{2}{|l|}{ ALCA } & \multicolumn{2}{|l|}{ CLCA } & \multicolumn{2}{|c|}{ Difference } \\
\hline & Ranking & $P t$ & Ranking & $P t$ & Pt & $\%$ \\
\hline Synthetic plaster - EPS & 1 & 4.86 & 1 & 5.20 & 0.34 & $7.0 \%$ \\
\hline Cavity wall - rock wool & 2 & 5.10 & 3 & 5.69 & 0.59 & $11.6 \%$ \\
\hline Cavity wall - PUR & 3 & 5.28 & 2 & 5.61 & 0.33 & $6.3 \%$ \\
\hline Facade panels - wooden structure & 4 & 7.44 & 5 & 8.28 & 0.84 & $11.3 \%$ \\
\hline Synthetic plaster - PUR & 5 & 7.74 & 4 & 7.45 & -0.29 & $-3.7 \%$ \\
\hline Synthetic plaster - rock wool & 6 & 10.07 & 6 & 11.41 & 1.34 & $13.3 \%$ \\
\hline Facade panels - aluminium structure & 7 & 14.89 & 7 & 14.05 & -0.84 & $-5.6 \%$ \\
\hline
\end{tabular}




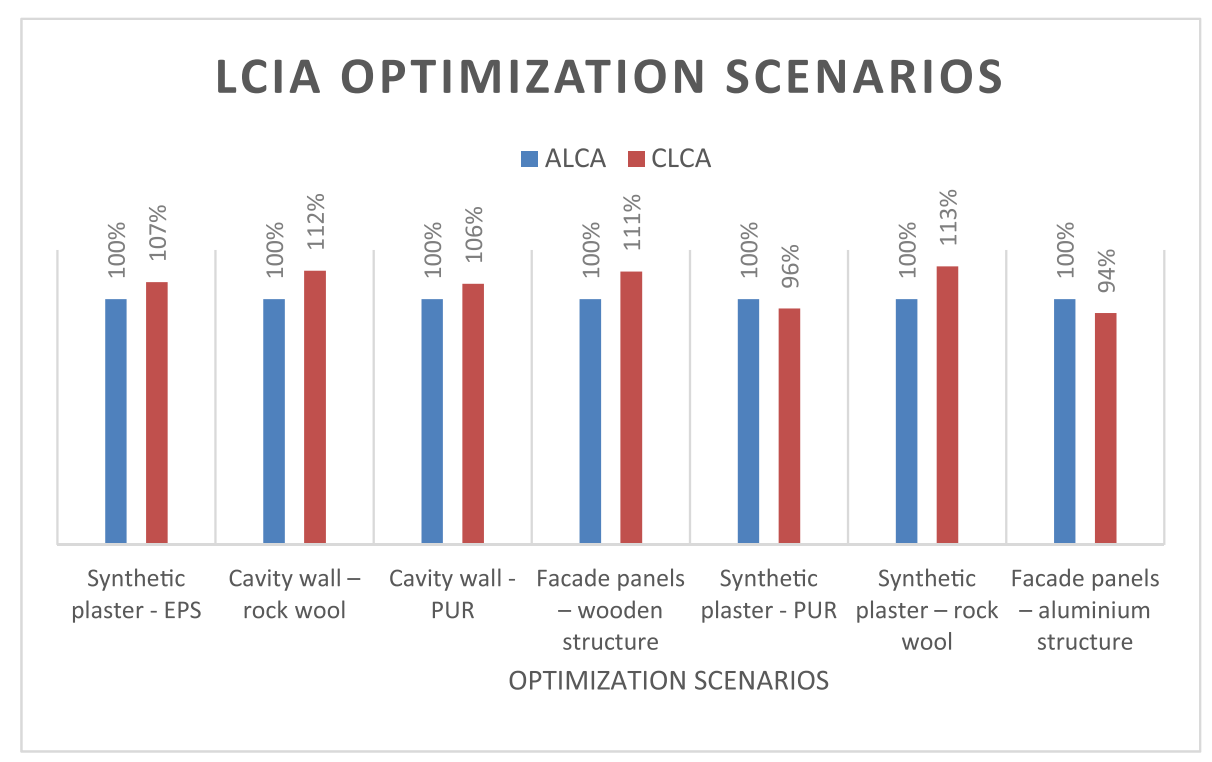

Fig. 5. LCIA of the optimization scenarios. ALCA is the reference scenario.

both cases, despite the relative short service life. The differences basically affect the ranking of place two to five. The main reasons for the changes are similar as for the contribution analysis, described in the previous paragraph. The difference here is that insulation and cladding systems combine multiple products, thus the results are aggregated. The discrepancies per material are therefore a bit damped. For example, there is not a clear preference to apply rock wool over PUR (see Fig. 5).

A final step is the inclusion of an extra scenario as sensitivity analysis. This additional model is a consequential one, but some assumptions where adopted from EPBE. This model can also be regard as an intermediate model. The logic of the selection of affected suppliers, handling multi-functionality and end-of-life remains the same, only all markets are delimited to Western Europe with the corresponding local transport scenarios. The results are shown for the life cycle phases and the contribution analysis (see Tables 3 and 4). The distribution over the life cycle phases demonstrates clearly the substitution approach at the endof-life, but also the significant lower impacts compared to the reference CLCA scenario.

Looking at the contribution analysis, the differences become more visible. The discrepancies are again the most pronounced at the highly ranked materials. Since the geographical definition of the markets and transport scenarios are the variables, the identification of the reason of the discrepancy is in most cases straight forward. Electricity production in Europe is in general more environmental friendly compared to other regions. This becomes in particular very clear at energy intensive processes without closed loop recycling such as cement based products. Transport on the other hand plays an important role for brick, one of the few materials with a higher impact for the sensitivity scenario. Since the brick sector was already identified as a European market, the same suppliers are already taken into account, but the EPBE transport scenario mainly assumes truck transport with a higher impact per ton-kilometer. To conclude, the sensitivity scenario shows clear similarities with the regular consequential model, some significant differences do occur.

\section{Discussion}

In the previous section, the results demonstrated a clear difference in environmental profile of the same case, depending on the applied model. Since each model has its own underlying reasoning it is obvious that such differences occur. The most important issue when comparing models is not necessarily the differences between results, but the direction the models point to and the research questions that can be answered accordingly. In general an attributional model is well suited to analyses the past or current situation of a system or static systems, so it is preferred to support decisions that reward or blame past actions. An example can be eco-taxation. While the consequential approach is preferred to analyze the impact of decisions, whether they concern small scale individual decisions or have an effect on societal level. In the case of the EPBE study, the goal and target group of the study is defined as: "Decision-makers, i.e. architects, engineering agencies, contractors, proprietors, project developers and government bodies, often lack the environmental information that is required for objective and transparent creation, selection or support of ecofriendly materials solutions. In addition, some manufacturers and distributors are unaware of the potential environmental impact that building materials have during their life cycle."(Debacker et al., 2013a). Actually the previous statement indicates that the study tries to support two types of decisions. The first one is to identify hotspots for improvement, starting with an assessment of current practice, the second one is to assist decision makers at different levels at making choices affecting the future situation. These are in fact two completely different situations and they should be modelled accordingly. The EPBE study follows an attributional logic and is therefore well suited for supporting the first kind of decisions, the hotspot identification of past and current practice. Notwithstanding, to improve current practice the future situation is affected and such strategies should be based on the results of a consequential model. The second goal of EPBE is to inform and support decision makers to improve current situation, which is a typical example where current decisions affect the future and a consequential model is more suitable. So the consequential model described in this research could be an added value to provide the right model for one of the two goals of the EPBE study.

Since the results presented in this paper are more a proof-ofconcept rather than a finalized research project, there are some limitations as well. Only one case has been investigated so far, albeit a representative one for newly built dwellings in Belgium. It would 
be premature to draw generalized conclusions based on these results for implementation on a larger scale. Scenarios that consider thorough renovation cycles during the use of a building could complement this study, since a life span of 60 years is currently applied, but in practice the life span is often longer and renovations should be taken into account as well.

To date, quantified uncertainties at the unit process level have largely been generated using the Pedigree approach only, disregarding inherent uncertainties (inaccurate measurements) and spread (variability around means due to averaging). As part of the EU FP7 SEAT project Henriksson et al. (2014) developed a method dealing with all three categories of dispersions. The method only deals with LCI unit process data, and not with LCIA or other data and neither with methodological choices such as FU, system boundaries or allocation. The sensitivity analysis demonstrates that within a certain modelling approach, other assumptions can affect the results. A limitation is that only one extra scenario has been added. In particular for the consequential approach, criteria to define the market delimitation and for identifying marginal suppliers can have a big effect on the outcome. Therefore, rather than focusing on process uncertainty only, a future research opportunity is to address model uncertainty by developing scenarios on a transparent and consistent way. But not only modelling assumptions should be assessed more extensively, also building related scenarios should be expanded. In this research, different façade finishing systems were examined. But multiple possibilities for structural systems, building type and technical services should be taken into account as well.

This research study, furthermore, is based on a process LCA, which tends to underestimate overall environmental impact. All examined scenarios are composed of similar materials and structural concepts, so it is assumed that comparison still provides useful insights, but interesting future work could complement this research using a hybrid I/O approach (Crawford, 2008; Suh, 2006; Treloar, 1997).

\section{Conclusions}

Multiple studies and guidance documents exist concerning environmental issues in the construction sector. However, nearly all of them are following an attributional approach. Both attributional and consequential approaches include models with different underlying assumptions and they try to answer different research questions. So it is important for decision-makers to have the right information at their disposal, otherwise this can induce wrong or no relevant conclusions. To date, the most elaborate study in Flanders, 'Environmental profile of building elements' (EPBE), published by the Public Waste Agency of Flanders, is an attributional study. The study aims at informing different kind of decisionmakers (building client, building professionals and policy makers) and to assist manufacturers and distributors at identifying hotspots for improving industrial systems. However, if the results of the study are used to support future policy or to improve a production system, a consequential model would be more appropriate. This paper describes a consequential model that can complement the EPBE study to provide the required information for all types of decisions. To demonstrate the relevance of this addition, both models have been applied on the same case, a new dwelling in Niel in the north of Belgium. A conceptual optimization scenario of insulated exterior cladding systems is discussed as well.

The results of the entire life cycle indicate potential differences, in direct relationship to the underlying modelling assumption. For example the negative impact of the end-of-life phase due to the recycling potential of the consequential model. The discrepancies become more pronounced when looking at the separate materials to avoid the effect being damped as a consequence of the aggregation of the results. Especially the three most contributing materials (steel, concrete and brick) show clear differences. In accordance with the Belgian tradition with a focus on massive structures, this can have a big influence on the development of possible improvements. The optimization scenarios underline previous statement, since the ranking of the different solutions changes according to the chosen approach. Although the differences might not be significant in some cases, it still emphasizes the importance of the applied approach on the results and conclusions.

Finally, to enhance a sustainable society it is needed that policy is focused on the entire life cycle of buildings instead of merely on energy efficiency, but this should happen in a proper manner with the right choice of approach depending on the specific objectives. Unfortunately currently this is not the case in the construction sector, which mainly focuses on attributional LCA.

\section{Acknowledgment}

The authors like to thank Bo Weidema and Massimo Pizzol from Aalborg University for their advice, review of the paper and profound feedback.

\section{Appendix A. Supplementary data}

Supplementary data related to this article can be found at http:// dx.doi.org/10.1016/j.jclepro.2016.08.114.

\section{References}

Adalberth, K., 1997. Energy use during the life cycle of single-unit dwellings: examples. Build. Environ. 32, 321-329. http://dx.doi.org/10.1016/S0360-1323(96) 00069-8.

Allacker, K., 2012. Environmental and economic optimisation of the floor on grade in residential buildings. Int. J. Life Cycle Assess. 17, 813-827. http://dx.doi.org/ 10.1007/s11367-012-0402-2.

Annemans, M., Verhaegen, M., Debacker, W., 2012. Life cycle assessment in architecture practice : the impact of materials on a flemish care home. In: International Symposium on Life Cycle Assessment and Construction, July 10-12, Nantes, France, pp. 205-212.

Asif, M., Muneer, T., Kelley, R., 2007. Life cycle assessment: a case study of a dwelling home in Scotland. Build. Environ. 42, 1391-1394. http://dx.doi.org/10.1016/ j.buildenv.2005.11.023.

Bawden, K.R., Williams, E.D., Babbitt, C.W., 2016. Mapping product knowledge to life cycle inventory bounds:a case study of steel manufacturing. J. Clean. Prod. 113, 557-564. http://dx.doi.org/10.1016/j.jclepro.2015.10.014.

BCIS, 2006. Life Expectancy of Building Components. Surveyors' Experiences of Buildings in Use. A Practical Guide, second ed. BCIS, London.

Blengini, G.A., Di Carlo, T., 2010. Energy-saving policies and low-energy residential buildings: an LCA case study to support decision makers in Piedmont (Italy). Int. J. Life Cycle Assess. 15, 652-665.

Blengini, G.A., Di Carlo, T., 2009. The changing role of life cycle phases, subsystems and materials in the LCA of low energy buildings. Energy Build. 42, 869-880.

BREEAM International, 2013. BREEAM International New Construction - Technical Manual: SD5075 (Watford).

Buyle, M., Audenaert, A., Braet, J., Debacker, W., 2015. Towards a more sustainable building stock: optimizing a flemish dwelling using a life cycle approach. Buildings 5, 424-448. http://dx.doi.org/10.3390/buildings5020424.

Buyle, M., Audenaert, A., De Cleyn, S.H., 2011. Material optimization of low-energy flats using the LCA eco-indicator 99 method: impact of materials and EOL. In: 2nd International Conference of the Institute for Environment, Engineering, Economics and Applied Mathematics: Urban Sustainability, Cultural Sustainability, Green Development, Green Structures and Clean Cars (USCUDAR 2011), September 26-28, Prague, Czech, p. 6.

Buyle, M., Braet, J., Audenaert, A., 2014. Life cycle assessment of an apartment building : comparison of an attributional and consequential approach. In: 6th International Conference on Sustainability in Energy and Buildings, SEB - 14.

Buyle, M., Braet, J., Audenaert, A., 2013. Life cycle assessment in the construction sector: a review. Renew. Sustain. Energy Rev. 26, 379-388. http://dx.doi.org/ 10.1016/j.rser.2013.05.001.

Chau, C.K., Leung, T.M., Ng, W.Y., 2015. A review on life cycle assessment, life cycle energy assessment and life cycle carbon emissions assessment on buildings. Appl. Energy 143, 395-413. http://dx.doi.org/10.1016/j.apenergy.2015.01.023.

Crawford, R.H., 2008. Validation of a hybrid life-cycle inventory analysis method. J. Environ. Manag. 88, 496-506. http://dx.doi.org/10.1016/ 
j.jenvman.2007.03.024.

Curran, M., Mann, M., Norris, G., 2005. The international workshop on electricity data for life cycle inventories. J. Clean. Prod. 13, 853-862. http://dx.doi.org/ 10.1016/j.jclepro.2002.03.001.

Cyx, W., Renders, N., Van Holm, M., Verbeke, S., 2011. IEE TABULA - Typology Approach for Building Stock Energy Assessment. Mol.

Debacker, W., Allacker, K., De Troyer, F., Janssen, A., Delem, L., Peeters, K., De Nocker, L., Spirinckx, C., Van Dessel, J., 2013a. Environmental Profile of Building Elements (Mechelen, Belgium).

Debacker, W., Allacker, K., Spirinckx, C., Geerken, T., De Troyer, F., 2013b. Identification of environmental and financial cost efficient heating and ventilation services for a typical residential building in Belgium. J. Clean. Prod. 57, 188-199. http://dx.doi.org/10.1016/j.jclepro.2013.05.037.

Debacker, W., Annemans, M., Van Holm, M., Spirinckx, C., Heyrman, L., Verhaegen, M., 2011. Improving the environmental impacts of a typical flemish retirement home : a life cycle approach, in: World Sustainable Building Conference (SB11), Helsinki, Finland.

Earles, J.M., Halog, A., 2011. Consequential life cycle assessment: a review. Int. J. Life Cycle Assess. 16, 445-453. http://dx.doi.org/10.1007/s11367-011-0275-9.

Ekvall, T., Weidema, B., 2004. System boundaries and input data in consequential life cycle inventory analysis. Int. J. Life Cycle Assess. 9, 161-171.

Eriksson, L.O., Gustavsson, L., Hänninen, R., Kallio, M., Lyhykäinen, H., Pingoud, K., Pohjola, J., Sathre, R., Solberg, B., Svanaes, J., Valsta, L., 2012. Climate change mitigation through increased wood use in the European construction sectortowards an integrated modelling framework. Eur. J. For. Res. 131, 131-144. http://dx.doi.org/10.1007/s10342-010-0463-3.

European Commission - Joint Research Centre - Institute for Environment and Sustainability, 2010. ILCD Handbook: General Guide to Life Cycle Assessment-Detailed Guidance, first ed. Publications Office of the European Union, Luxembourg. http://dx.doi.org/10.2788/38479.

European committee for Standardiation, 2012. EN 15804:2012-Sustainability of Construction Works - Environmental Product Declarations - Core Rules for the Product Category of Construction Products.

European committee for Standardiation, 2011. EN 15978:2011-Sustainability of Construction Works - Assessment of Environmental Performance of Buildings - Calculation Method.

European Parliament, 2011. Regulation (EU) No 305/2011. Off. J. Eur. Union 5-43 (04.04.11.).

European Parliament, 2010. Directive 2010/31/EU of the European parliament and of the council on the energy performance of buildings (recast). Off. J. Eur. Union 13-35 (18.06.10.)

European Parliament, 2008. Directive 2008/98/EC of the European parliament and of the council of on waste and repealing certain directives (waste framework). Off. J. Eur. Union 2008, 3-30 (19 09 08.).

European Parliament, 2002. Directive 2002/91/EC of the European parliament and of the council on the energy performance of buildings. Off. J. Eur. Union 65-71 (04.01.2003.).

Feiz, R., Ammenberg, J., Baas, L., Eklund, M., Helgstrand, A., Marshall, R., 2015. Improving the $\mathrm{CO}_{2}$ performance of cement, part I: utilizing life-cycle assessment and key performance indicators to assess development within the cement industry. J. Clean. Prod. 98, 272-281. http://dx.doi.org/10.1016/ j.jclepro.2014.01.103.

Finnveden, G., Eldh, P., Johansson, J., 2006. Wheighting in LCA based on ecotaxes. Development of a mid-point method and experiences from case studies. Int. J. Life Cycle Assess. 11, 81-88.

Finnveden, G., Hauschild, M.Z., Ekvall, T., Guinée, J., Heijungs, R., Hellweg, S., Koehler, A., Pennington, D., Suh, S., 2009. Recent developments in life cycle assessment. J. Environ. Manag. 91, 1-21.

Gerilla, G., Teknomo, K., Hokao, K., 2007. An environmental assessment of wood and steel reinforced concrete housing construction. Build. Environ. 42, 2778-2784. http://dx.doi.org/10.1016/j.buildenv.2006.07.021.

Goedkoop, M., Heijungs, R., Huijbregts, M., De Schryver, A., Struijs, J., van Zelm, R., 2012. ReCiPe 2008: A Life Cycle Impact Assessment Method Which Comprises Harmonised Category Indicators at the Midpoint and the Endpoint Level. Ministry of Housing, Spatial Planning and Environment, Den Haag, The Netherlands.

Haas, M., Blass, J., 2015. NIBE's Tabellenboek 2015 Milieuclassificaties Bouwproducten (NIBEs Book of Tables 2015 Environmental Classifiications of Construction Products). Samenwerkende Uitgevers VOF, Bussem, The Netherlands.

Henriksson, P.J.G., Guinée, J.B., Heijungs, R., De Koning, A., Green, D.M., 2014. A protocol for horizontal averaging of unit process data - including estimates for uncertainty. Int. J. Life Cycle Assess. 19, 429-436. http://dx.doi.org/10.1007/ s11367-013-0647-4.
Heylen, K., Le Roy, M., Vanden Broucke, S., Vandekerckhove, B., Winters, S., 2007 Wonen in Vlaanderen: De resultaten van de woonsurvey 2005 en de uitwendige Woonschouwing 2005 (Living in Flanders: The results of the housing survey 2005 and the exterior housing inspection 2005) (Brussels, Belgium).

Himpe, E., Trappers, L., Debacker, W., Delghust, M., Laverge, J., Janssens, A., Moens, J., Van Holm, M., 2013. Life cycle energy analysis of a zero-energy house. Build. Res. Inf. 41, 435-449. http://dx.doi.org/10.1080/09613218.2013.777329.

Marceau, M.L., VanGeem, M., 2006. Comparison of the life cycle assessments of an insulating concrete form house and a wood frame house. J. ASTM Int. 3, 1-11. http://dx.doi.org/10.1520/JAI13637.

Matasci, C., 2006. Life Cycle Assessment of 21 Buildings: Analysis of the Different Life Phases and Highlighting of the Main Causes of Their Impact on the Environment. ETH Zürich.

Mithraratne, N., Vale, B., 2004. Life cycle analysis model for New Zealand houses. Build. Environ. 39, 483-492.

Ortiz-Rodríguez, O., Castells, F., Sonnemann, G., 2010. Life cycle assessment of two dwellings: one in Spain, a developed country, and one in Colombia, a country under development. Sci. Total Environ. 408, 2435-2443. http://dx.doi.org/ 10.1016/j.scitotenv.2010.02.021.

Peuportier, B.L.P., 2001. Life cycle assessment applied to the comparative evaluation of single family houses in the French context. Energy Build. 33, 443-450.

Public Waste Agency of Flanders, 2015. Ecolizer Designtool [WWW Document]. http://www.ecolizer.be (accessed 20.08.15.).

Ramesh, T., Prakash, R., Shukla, K.K., 2010. Life cycle energy analysis of buildings: an overview. Energy Build. 42, 1592-1600.

Rickwood, P., Glazebrook, G., Searle, G., 2008. Urban structure and energy-a review. Urban Policy Res. 26, 57-81. http://dx.doi.org/10.1080/ 08111140701629886.

Sandin, G., Peters, G.M., Svanström, M., 2014. Life cycle assessment of construction materials: the influence of assumptions in end-of-life modelling. Int. J. Life Cycle Assess. 19, 723-731. http://dx.doi.org/10.1007/s11367-013-0686-x.

Schmidt, J.H., 2015. Life cycle assessment of five vegetable oils. J. Clean. Prod. 87, 130-138. http://dx.doi.org/10.1016/j.jclepro.2014.10.011.

Sharma, A., Saxena, A., Sethi, M., Shree, V., 2011. Life cycle assessment of buildings: a review. Renew. Sustain. Energy Rev. 15, 871-875. http://dx.doi.org/10.1016/ j.rser.2010.09.008.

Statistics Belgium, 2014. Kerncijfers 2014, Statistisch Overzicht Van België (Key figures 2014, Statistical overview of Belgium) (Brussels, Belgium).

Statistics Belgium, 2012. Distributie Van Drinkwater in België (1993-april 2012) (Distribution of mains water in Belgium (1993-April 2012)) (Brussels, Belgium).

Stephan, A., Crawford, R.H., de Myttenaere, K., 2013. A comprehensive assessment of the life cycle energy demand of passive houses. Appl. Energy 112, 23-34. http://dx.doi.org/10.1016/j.apenergy.2013.05.076.

Stephan, A., Crawford, R.H., De Myttenaere, K., 2012. Towards a comprehensive life cycle energy analysis framework for residential buildings. Energy Build. 55, 592-600. http://dx.doi.org/10.1016/j.enbuild.2012.09.008.

Suh, S., 2006. Critical review system boundary selection in life-cycle inventories using hybrid approaches. Environ. Sci. Technol. 38, 657-664.

Treloar, G.J., 1997. Extracting embodied energy paths from input-output tables: towards an input-output-based hybrid energy analysis method. Econ. Syst. Res. 9, 375-391. http://dx.doi.org/10.1080/09535319700000032.

United Nations Environmental Programme, Sustainable Buildings and Climate Initiative, 2010. Common Carbon Metric for Measuring Energy Use and Reporting Greenhouse Gas Emissions from Building Operations (Paris).

United Nations Environmental Programme, Sustainable Buildings and Climate Initiative, 2009. Buildings and Climate Change: a Summary for Decision-makers (Paris).

Vieira, P.S., Horvath, A., 2008. Assessing the end-of-life impacts of buildings. Environ. Sci. Technol. 42, 4663-4669. http://dx.doi.org/10.1021/es0713451.

Vissering, C.L., Janssen, R., Liebregts, M.A.A.M., Staub, A., van Nunen, H., 2011. Levensduur Van Bouwproducten - Methode Voor Referentiewaarden (Life expectancy of building components - method for reference values). SBR, Rotterdam.

Weidema, B.P., 2003. Market Information in Life Cycle Assessment. Environmental Project No. 863. Copenhagen.

Weidema, B.P., Bauer, C., Hischier, R., Mutel, C., Nemecek, T., Reinhard, J. Vadenbo, C.O., Wenet, G., 2013. Overview and Methodology. Data Quality Guideline for the Ecoinvent Database Version 3, Swiss Center For Life Cycle Inventories. St. Gallen, Switzerland.

Weidema, B.P., Ekvall, T., Heijungs, R., 2009. Guidelines for Application of Deepened and Broadened LCA. Deliverable D18 of Work Package.

Zamagni, A., Guinée, J., Heijungs, R., Masoni, P., Raggi, A., 2012. Lights and shadows in consequential LCA. Int. J. Life Cycle Assess. 17, 904-918. http://dx.doi.org/ 10.1007/s11367-012-0423-X. 